\title{
Indicadores e Análise Multidimensional do Processo de Integração do Cone Sul
}

\author{
A multidimensional analysis of the process of regional \\ integration in the Southern Cone
}

ANDREA RIBEIRO HOFFMANN* MARCELO COUTINHO** REGINA KFURI***

Rev. Bras. Polít. Int. 51 (2): 98-116 [2008]

\section{Introdução}

No presente trabalho se desenvolve indicadores de integração regional com o principal objetivo de apresentar uma analise multidimensional do Mercosul no período de 1991 a 2006. A pesquisa parte da premissa que o Mercosul não pode ser considerado um caso sui generis de integração regional, e sim um exemplo de organização de integração regional assim como, por exemplo, a União Européia ou a Comunidade Andina de Nações. Embora cada uma dessas organizações possua características e dinâmicas particulares, e se encontre em momentos distintos de seu processo de integração, elas são entidades passíveis de serem comparadas.

A integração regional é definida neste trabalho como "um processo dinâmico de intensificação em profundidade e abrangência das relações entre atores levando à criação de novas formas de governança político-institucionais de escopo regional" (Herz \& Ribeiro Hoffmann, 2004: 168). É importante destacar que os atores envolvidos em um processo de integração podem ser governamentais ou não-governamentais, e além disso, podem ser nacionais, subnacionais ou transnacionais. Outro componente importante desta definição é que ao se integrar (regionalmente), os atores passam a fazer parte de um sistema político, de tomada de decisão, comum. Este conceito de integração regional

* Professora do Instituto de Relações Internacionais da Pontifícia Universidade Católica do Rio de Janeiro - IRI-PUC-Rio (andrearh@puc-rio.br).

** Doutor em Ciência Política pelo Instituto Universitário de Pesquisa do Rio de Janeiro - Iuperj e coordenador do Observatório Político Sul-Americano - OPSA/Iuperj (mcoutinho@iuperj.br).

*** Professora do Instituto de Relaçōes Internacionais da Pontifícia Universidade Católica do Rio de Janeiro IRI-PUC-Rio e pesquisadora do Observatório Político Sul-Americano-OPSA/Iuperj (reginakfuri@puc-rio.br). 
envolve, portanto, a criação de organizações internacionais formais, estabelecidas em um acordo constituinte, e que possuem sedes físicas. No entanto, ela não se restringe a instituiçôes formais, ela engloba também, normas, práticas e instituições informais. Neste contexto, torna-se extremamente importante se definir instituições (regionais) e processos de institucionalização. ${ }^{1}$

$\mathrm{O}$ presente trabalho adota as definições de instituições e de processo de institucionalização de Samuel Huntington (1975). Ele define instituições como padrões de comportamento estáveis, válidos e recorrentes, e abrangem organizaçôes formais e procedimentos. Para o autor, as comunidades políticas em sociedades complexas dependem da força das instituiçōes políticas, que dependem, por sua vez, da extensão do apoio dado a elas, ou seja, a medida em que elas abrangem as atividades da sociedade, e do seu nível de institucionalização (Huntington 1975:24).

Processo de institucionalização é definido como um "processo através do qual as organizações e os processos adquirem valor e estabilidade" (op. cit.: 24). O autor distingue quatro critérios de institucionalização: adaptabilidade, complexidade, autonomia e coesão. A respeito da adaptabilidade, Huntington defende que quanto mais adaptáveis forem as instituições, maior o nível de institucionalização. Adaptabilidade é uma função dos desafios do ambiente e da idade, e o êxito na adaptação abre caminho para adaptações bem sucedidas aos desafios ambientais subseqüentes. A idade pode ser medida de três maneiras: cronologicamente (quanto maior o tempo de existência, mais institucionalizada é a instituição), por geração (quanto mais freqüentemente a instituição tiver passado por transições de dirigentes pacificamente, maior sua institucionalização), ou em termos funcionais (uma organização que tiver se adaptado e sobrevivido a mudanças em seu meio e funçôes principais será mais institucionalizada). Quanto ao segundo critério, a complexidade, o autor defende que quanto mais complexa a instituição, maior seu nível de institucionalização. A complexidade pode envolver tanto a multiplicação de subunidades, como de objetivos, e quanto mais complexa for a instituição, mais meios para se renovar e adaptar ela terá. O terceiro critério, autonomia, é definido como a extensão em que a instituição existe independentemente de agrupamentos sociais e outras instituições políticas. A autonomia da instituição pode, portanto, ser medida pela extensão em que ela possui valores e interesses próprios, distinguíveis dos das outras instituições e forças sociais. Finalmente, quanto maior a coesão e união da instituição, ou seja, sua capacidade de coordenação e disciplina, maior sua institucionalização (op. cit.: 23-36).

Uma das vantagens de se adotar a definição de instituição de Huntington, é o fato dela não enfatizar a questão da supranacionalidade, ainda que este esteja relacionado ao critério de autonomia. A importância da supranacionalidade

1 Para uma discussao aprofundada sobre a definicao de instituicao e de processo de institucionalização na literatura de Relacoes Internacionais veja Coutinho, Ribeiro Hoffmann \& Kfuri 2007. 
costuma ser supervalorizada devido à importância atribuída a esta característica pelo neo-funcionalismo, uma das mais referidas perspectivas de integração regional. O neo-funcionalismo, no entanto, embora em suas origens tenha tido a ambição de se consolidar como uma teoria geral de integração regional, acabou se restringindo ao caso europeu, tendo, portanto, pouco valor para uma analise que pretende poder ser aplicada em outros processos de integração regional, em particular, o Mercosul (Haas 1967, Malamud 2003).

Já outro conceito relacionado a definição de instituições e processos de institucionalização não enfatizado por Huntington, mas que merece ser destacado é o conceito de legalização, ou judicialização. Alguns autores definem legalização como uma forma específica de institucionalização, e que pode ser analisada com base no grau de obrigação que as normas impóem sobre os Estados, na precisão de seu conteúdo; e no nível de delegação de poderes dos Estados para terceiros na formulação, interpretação e implementação das normas (Abott et al 2000). Definiçōes de legalização menos formalistas enfatizam as práticas, normas informais, e a legitimidade das normas (Finemore e Toope 2001). Outro conceito próximo ao de legalização, bastante referido nos estudos de integração regional, sobretudo a União Européia, é o de constitucionalização (Rittberger e Schimmelfenig 2006).

Finalmente, um último aspecto importante sobre o nível de cooperação/ integração de um processo de integração regional como definido neste trabalho, é que ele não pode ser avaliado de uma forma compacta, única, e sim desmembrado em várias características particulares, que podem ser vistas como indicadores temáticos. Para que o nível total de integração possa ser analisado, e sobretudo, explicado, seria necessário se atribuir a importância relativa de cada indicador, que por sua vez, somente pode ser determinada a partir de premissas teóricas que busquem explicar a dinâmica dos processos de integração. ${ }^{2}$ Embora o presente trabalho conduza uma análise do nível de integração regional do Mercosul ao longo do tempo, não é atribuída importância relativa a nenhum indicador específico. A análise é conduzida apenas a partir de uma comparação no tempo dos indicadores apresentados.

Antes de conduzir a análise do nível de integração regional do Mercosul entre 1991 e 2006, o artigo apresenta os indicadores de integração regional, e sua operacionalização. Algumas reflexões finais são apresentadas na última sessão.

\section{Indicadores de integração regional e sua operacionalização}

Como afirmado acima, o principal objetivo deste artigo é analisar o nível de integração do Mercosul. Ele não tem a ambição de construir uma teoria que

2 As principais perspectivas teóricas de integração regional são o neo-funcionalismo, intergovernamentalismo liberal, neo-institucionalimo (racional, histórico e sociológico/construtivismo), e governanca multinível. Sobre as perspectivas ver Wiener \& Diez 2004, Rosamond 2000 e Sangiovanni 2006. 
explique avanços e retrocessos dos processos de integração, não busca selecionar variáveis e comparar seu poder explicativo em diferentes casos de processos de integração ou diferentes períodos históricos de um mesmo processo de integração. Desta forma, a seleção de indicadores não se restringe a variáveis apontadas pelas teorias de integração, ela procura ser o mais abrangente possível, desde que não se torne redundante. Os dados empíricos coletados poderiam potencialmente ser utilizados para testar hipóteses de diferentes teorias, ou alternativamente, para desenvolver, de forma indutiva, uma nova teoria, mas isso seria outro trabalho.

Os indicadores selecionados são brevemente descritos abaixo. Eles estão agrupados em três dimensões: econômica, político-institucional e social. As dimensões englobam atividades dos governos e da sociedade civil, sendo que a última é definida de forma ampla, incorporando entidades sem e com finslucrativos. Estas dimensões, e alguns dos indicadores selecionados neste trabalho, foram utilizadas por Joseph Nye em um estudo comparativo dos processos de integração regional (Nye, 1970). Este autor, que foi um dos primeiros estudiosos da integração regional a defender a desagregação do conceito de integração, destacou que uma das principais vantagens do método é a compreensão de que não apenas diferentes aspectos podem progredir em ritmos diferentes, mas também que é possível que haja integração em determinadas áreas e desintegração em outras.

Em relação aos indicadores econômicos, a maioria dos estudos de integração regional se baseia na tipologia desenvolvida por Bela Belassa em uma obra seminal sobre as teorias de integração econômica "área de livre comercio", "união aduaneira", "mercado comum", "união econômica" e "integração econômica total" (Belassa 1961). No caso do Mercosul, os tratados afirmam o objetivo alcançar apenas o nível de mercado comum. No entanto, até o presente momento o Mercosul é caracterizado como uma união aduaneira imperfeita. Por este motivo, os indicadores selecionados se limitam aos relativos à livre circulação de fatores, e o volume de comércio relativo incorporado a tarifa externa comum. Os indicadores abrangem as taxas de crescimento absoluta, e relativa ao resto do mundo.

No que se refere aos indicadores político-institucionais, um primeiro grupo de indicadores são os relativos ao desenho institucional do bloco. Essas características determinam em grande medida o perfil do bloco como intergovernamental ou supranacional. Essas características, no entanto, não são percebidas como estanques no tempo. A partir de uma visão dinâmica da intergovernabilidadesupranacionalidade, pode-se compreender que uma organização de integração regional pode ter características intergovernamentais e supranacionais ao mesmo tempo, e que essas características possam ser alteradas ao longo do tempo por meio de práticas informais e reformas institucionais. No caso do Mercosul, as decisões em todos os órgãos e áreas temáticas é o consenso, mas esta regra pode mudar. Da mesma forma, o sistema judiciário, embora não seja comunitário, tem adquirido mais poder vinculatório. No que se refere ao volume total de normas aprovadas nos órgãos deliberativos, embora este número seja importante, o mais 
relevante para o Mercosul parece ser o volume de normas incorporadas, dado que historicamente há um grande hiato entre os dois (Pena 2003).

Outra característica político-institucional importante seria um indicador da utilização do sistema de solução de controvérsia no caso da existência de conflitos. Enquanto na União Européia, por exemplo, todos os casos sob competência da Corte Européia de Justiça passam pelas normas regionais, seja quando são diretamente trazidos a ela, ou via cortes nacionais, dado que o direito comunitário é hierarquicamente superior ao doméstico, e de aplicação imediata, no Mercosul, este não é o caso, como exemplificado no recente caso das "papeleiras" (Magalhães 2006). Outro indicador relevante é a representação do bloco em instituições internacionais, ou seja, o grau de formalização da representação do bloco em outras instituições internacionais tais como a OMC, a ONU ou a OEA. Três níveis de representação poderiam ser definidos: membro pleno; status formal de observador; participante informal (Ribeiro Hoffmann 2007).

Finalmente, é importante averiguar se as instituições dos governos nacionais (federais, estaduais ou municipais) têm órgãos ou indivíduos responsáveis para lidar com assuntos de integração regional. No caso do Mercosul, parece estar havendo uma mudança neste sentido, já que várias prefeituras e ministérios têm criado cargos de assessores internacionais. As subunidades federativas têm cada vez mais se organizado coletivamente para participar do processo decisório, sendo a criação recente do Foro Consultivo de Municípios, Estados Federados e Províncias, um exemplo desta atividade (Pasquariello Mariano 2007).

No que se refere aos indicadores sociais, o primeiro é a livre circulação de pessoas, que também estaria dentro do indicador de Belassa de livre circulação de fatores, mas foi incorporado aqui como indicador social, pois envolve, além da circulação por motivos de emprego, também turismo e estudos. Outro indicador para a circulação de estudantes, embora menos ideal, pois indicaria a possibilidade de circulação e não a circulação de fato, seria a harmonização do sistema educacional. Outra característica importante é a existência de atividades culturais, aqui o indicador ideal seria a quantidade de eventos, mas na impossibilidade de obtenção deste dado, um substituto seriam as políticas de promoção cultural entre os Estados membros. A criação de órgãos de representação de empresários ou trabalhadores regional, criação de ONGs regionais também seria um indicador importante. Finalmente, entre os indicadores sociais estaria a existência ou não de uma identidade comum regional. A avaliação deste indicador poderia ser obtida através de pesquisas de opinião, tais como a realizada pelo Latinobarômetro. ${ }^{3}$

\section{O nível de integração do Mercosul entre 1991 e 2006}

Antes de apresentar os dados empíricos da pesquisa é preciso destacar uma limitação da análise conduzida, que se deveu à impossibilidade de acesso ou mesmo

3 Para detalhes ver http://www.latinobarometro.org. 
a inexistência de fontes. Com isso, a análise do nível de integração do Mercosul apresentada se baseia nos seguintes indicadores: na área social, a circulação de pessoas foi analisada a partir dos fluxos de turistas entre os quatro países do bloco. $\mathrm{Na}$ área econômica, foram analisados dados de comércio intra e extrabloco, e o PIB dos países. Os indicadores institucionais são a estrutura institucional do Mercosul, a internalização da normativa, a resolução de disputas, e representação externa do bloco.

Para acompanhar a evolução da estrutura institucional do Mercosul, as fontes consultadas foram os tratados, protocolos e decisões do Conselho do Mercado Comum (CMC). Como indicadores relativos à incorporação da normativa aos ordenamentos jurídicos internos, foram analisadas as diretrizes da Comissão de Comércio do Mercosul (CCM) disponíveis no site da Secretaria do Mercosul ${ }^{4}$. As resoluções de disputas foram analisadas a partir dos laudos dos mecanismos de solução de controvérsias do bloco e das instâncias globais tais como a Organização Mundial de Comércio e a Corte Internacional de Justiça de Haia. É analisado se o contencioso se resolveu a contento das partes dentro dos mecanismos institucionais do Mercosul, ou se foi levado a outra organização mundial, o que pode significar menor grau de confiança na instituição regional. A representação externa é analisada por meio dos padrões de votação na Assembléia Geral da Organização das Naçôes Unidas (ONU). Considera-se a votação foi conjunta quando os quatro países do Mercosul votaram coincidentemente - seja a favor ou contra a resolução - ou quando todos estiveram ausentes da votação. Quando há alguma divergência, mesmo que seja apenas a ausência de um dos quatro países, considera-se que votaram em separado5.

A análise dos dados sugere que o processo de integração do Mercosul pode ser dividido em três fases. A primeira pode ser chamada de fase de formação e compreende o período entre 1991 e 1997, durante o qual é constituída a estrutura institucional do bloco. A ênfase é dada ao aspecto comercial do processo de integração, com a criação de órgãos destinados a tratar do tema. A segunda fase, que vai de 1998 a 2002, foi uma fase de crise, como um reflexo da crise econômica pela qual os países passavam. Uma terceira fase se delineia a partir de 2003, quando há uma retomada do processo de integração, coincidindo com uma renovação na política doméstica dos países, com governos mais alinhados com a esquerda chegando ao poder: no Brasil, Luis Inácio Lula da Silva, na Argentina, Néstor Kirchner, e no Uruguai, Tabaré Vázquez. Os três novos governos destacaram a importância da integração regional em suas políticas externas, mas com uma mudança de paradigma: aos poucos a idéia de um Mercosul puramente comercial vai dando lugar a uma preocupação maior com a integração física e social, e a institucionalização. Cada uma destas fases é analisada em detalhes a seguir.

\footnotetext{
4 http://www.mercosur.int/msweb/

5 Os dados relativos às votaçōes na Assembléia Geral da ONU foram obtidos nos sites: http://ucdata.berkeley. edu:7101/new_web/VoteWorld/voteworld/index.html e http://home.gwu.edu/ -voeten/
} 


\section{$1^{a}$ Fase (1991 a 1997): a criação do Mercosul}

\section{Institucional}

Ao criar o Mercosul em 1991, os países-membros optaram por um desenho institucional intergovernamental, criando órgãos compostos por representantes dos poderes executivos dos Estados-membros, e um sistema de tomada de decisão por consenso. Segundo o estabelecido no Tratado de Assunção, o Mercosul contaria com dois órgãos: o Conselho do Mercado Comum (CMC) e o Grupo Mercado Comum (GMC). O CMC seria o órgão superior do Mercosul, formado pelos ministros de Relaçóes Exteriores e pelos ministros de Economia de cada um dos Estados-membros, além da participação dos presidentes dos Estados membros em pelo menos uma reunião anual. Ao CMC estava designada a condução política do bloco e a tomada de decisões para a constituição do Mercado Comum.

OGMC foi instituído como um órgão executivo, composto por representantes dos ministérios das Relações Exteriores e da Economia e dos Bancos Centrais, com as funçóes de zelar pelo cumprimento do Tratado, tomar as providências necessárias para o cumprimento das decisões adotadas pelo Conselho, propor medidas concretas para a aplicação do Programa de Liberação Comercial, com a coordenação de políticas macroeconômicas e a negociação de acordos frente a terceiros e fixar o programa de trabalho que assegure o avanço para a constituição do Mercado Comum. Foram criados subgrupos de trabalho para o cumprimento dessas funções. Esta seria a estrutura institucional do Mercosul responsável pelo período de transição para o estabelecimento do Mercado Comum, previsto para 31 de dezembro de 1994.

Segundo a determinação de Assunção, o Protocolo de Ouro Preto ${ }^{6}$, de dezembro de 1994, ampliou a estrutura institucional do bloco, com a criação de mais quatro órgãos: a Comissão de Comércio do Mercosul (CCM); a Comissão Parlamentar Conjunta (CPC); o Foro Consultivo Econômico-Social (FCES) e a Secretaria Administrativa do Mercosul (SAM). A CCM foi criada como um órgão encarregado de prestar assistência ao GMC, coordenado pelos ministérios das Relações Exteriores, encarregado de "velar pela aplicação dos instrumentos de política comercial comum acordados pelos Estados-Partes para o funcionamento da união aduaneira, bem como acompanhar e revisar os temas e matérias relacionados com as políticas comerciais comuns, com o comércio intraMercosul e com terceiros países"7.

A CPC foi estabelecida como um órgão de caráter consultivo, representativo dos Parlamentos dos Estados-Partes no âmbito do Mercosul e integrado por um número igual de parlamentares representantes de cada Estado-parte. Caberia à

6 Disponível em http://www.sice.oas.org/trade/mrcsrp/ourop/ouropinp.asp

7 Protocolo de Ouro Preto, disponível em http://2005.sice.oas.org/trade/mrcsrp/ourop/ourop_p. asp\#Cap\%EDtulo_I_ 
CPC "acelerar os procedimentos internos correspondentes nos Estados-Partes para a pronta entrada em vigor das normas emanadas dos órgãos do Mercosul previstos no Artigo 2 deste Protocolo (de Ouro Preto)" ${ }^{8}$. O FCES foi criado para ser o órgão de representação de setores econômicos e sociais, com função consultiva e submetido ao GMC.

A SAM foi criada como órgão de apoio operacional aos demais órgãos do Mercosul e tem sede permanente em Montevidéu. Entre as atribuições originais da SAM, estavam a organização das reuniōes do GMC, do CMC e da CCM, a publicação das decisões adotadas no âmbito do Mercosul e o acompanhamento e informação sobre as normas emanadas dos órgãos do Mercosul incorporadas pelos Estados-partes aos seus ordenamentos jurídicos nacionais.

Apesar de ampliada, a estrutura institucional do Mercosul do Protocolo de Ouro Preto manteve as principais características. Ela continuou se baseando em um processo de tomada de decisão consensual, obrigatórias, mas devendo ser internalizadas de acordo com o ordenamento jurídico de cada Estado-membro, e não têm aplicação direta. $\mathrm{O}$ aspecto comercial é a tônica do projeto de integração e orienta a estruturação institucional do bloco neste período.

O sistema de solução de controvérsias do Mercosul foi institucionalizado pelo Protocolo de Brasília, em abril de 1993. O documento previa que as disputas deveriam, prioritariamente, ser negociadas diretamente entre as partes. Caso não fosse possível chegar a um acordo, as partes poderiam submeter a disputa à consideração do GMC. Finalmente, caso nenhuma solução fosse acordada, o Protocolo previa a possibilidade de recurso a tribunais arbitrais ad hoc, mecanismo reiterado pelo Protocolo de Ouro Preto.

A análise dos padrōes de votação na Assembléia Geral (AG) da ONU demonstra que havia, nessa fase, pouca preocupação em coordenar políticas ou apresentar posições coesas no âmbito das relações externas do bloco. Entre 1991 e 1996, há posições divergentes em relação a quase metade das votações. Em 1991, assim como em 1995 e 1996, houve mais votos não-coincidentes entre os quatro membros do que votos coincidentes. Do total de 509 votaçōes na AG entre 1991 e 1996, os quatro Estados- membros do Mercosul votaram da mesma forma em 258 , ou $51 \%$, e tiveram posiçõos divergentes em 251 , ou $49 \%$.

Com relação à vigência e internalização das normas regionais, entre 1994 e 1997, foram 56 diretivas. Desse total, 15 foram revogadas. Dentre as 41 restantes, 18 não requeriam incorporação aos ordenamentos jurídicos domésticos de nenhum dos quatro países. Dessas 41 diretivas que não foram revogadas, 24 entraram em vigor até 1997 . Ou seja, das 23 diretivas que precisavam de internalização, apenas seis foram de fato incorporadas.

8 Protocolo de Ouro Preto, disponível em http://2005.sice.oas.org/trade/mrcsrp/ourop/ourop_p. asp\#Cap\%EDtulo_I_ 


\section{Econômico}

A fase de formação do Mercosul também é uma fase de expansão do comércio entre seus membros. O volume total de comércio intrabloco em 1991 é de US\$ 10.201 milhôes. Em 1992, o volume de comércio entre os quatro países aumenta para US\$ 14.497 milhões. Esse aumento é proporcionalmente maior do que o aumento no comércio desses países com o resto do mundo, que sobe de US \$ 68.038 milhões, em 1991, para US\$ 74.846 milhões em 1992. O comércio intrabloco continua a crescer nos anos seguintes, chegando a US\$ 19.143 milhões em 1993, US \$ 23.712 milhões em 1994, US\$ 28.438 milhões em 1995 e US\$ 34.226 milhões em 1996. Proporcionalmente, a fatia do comércio relativo ao bloco cresce: enquanto em 1991 o comércio com os países do Mercosul correspondia a $13 \%$ do total de comércio desses países, em 1997, o comércio intrabloco respondia por $23 \%$ do total.

Essa expansão contínua vai até 1997, quando o valor total das trocas dentro do bloco chega a US $\$ 41.074$ milhões, um valor quatro vezes maior que o de 1991. Nesse mesmo período, o comércio extra-regional também cresceu, mas em ritmo mais lento: de US \$ 68.038 milhões, em 1991, para US \$ 139.046 milhões, em 1997, um volume duas vezes maior.

\section{Social}

A circulação de pessoas intrabloco está representada nesse estudo somente através do número de turistas que circulam entre os quatro países do bloco. Esse número cresce, de 2,8 milhôes de pessoas em 1991 para 5 milhôes de pessoas em 1997, 75\%. Diferentemente de outros indicadores, esse movimento ascendente não muda a partir de 1998. A queda no número de turistas só vai acontecer a partir de 2001, o que será analisado adiante.

\section{$2^{a}$ Fase (1998 a 2002): crise no processo de integração}

\section{Institucional}

Durante o período compreendido entre 1998 e 2002, a estrutura existente continuou funcionando, mesmo no período de crise econômica e comercial. Uma prova disso está no número de diretivas da Comissão de Comércio que entraram em vigor nesse período. É interessante notar que muitas das diretivas criadas entre 1994 e 1997 foram internalizadas pelos países-membros nesse período. Entre 1998 e 2002 entraram em vigor 51 normas emanadas da Comissão, 14 delas eram normas que haviam sido criadas no período anterior. As 37 normas restantes foram criadas nesse período de crise e não necessitavam de incorporação por nenhum dos Estados-membros. A maior parte delas entrou em vigor nos anos de 2000 e 2002, foram 20 diretivas em 2000 e 14 em 2002. 
Em 1998 foi criado o Foro de Consulta e Concertação Política, único órgão criado nessa fase. $\mathrm{O}$ Foro, integrado por funcionários das chancelarias dos Estados Partes do Mercosul, tinha por objetivo aprofundar o diálogo entre os membros do Mercosul em temas de política externa e da agenda política comum, com a sistematização da cooperação política entre os Estados-partes, por meio da formulação de recomendações ao CMC'.

Os anos de 2000 e 2002 marcaram o esforço de fortalecimento do bloco. Em 2000, uma série de normas foi chamada de "Relançamento do Mercosul". Foram decisōes aprovadas no âmbito do CMC e que diziam respeito a acesso aos mercados, incorporação da normativa do Mercosul, melhorias no desempenho da SAM, aperfeiçoamento do Sistema de Solução de Controvérsias, tarifa externa comum, defesa comercial e da concorrência, coordenação macroeconômica, incentivos aos investimentos, à produção e à exportação, incluindo zonas francas, admissão temporária e outros regimes especiais e relacionamento externo ${ }^{10}$. Com relação este último aspecto, o relançamento do Mercosul buscou "reafirmar o compromisso dos Estados-Partes do Mercosul de negociar de forma conjunta acordos de natureza comercial com terceiros países ou blocos de países extra-zona nos quais se outorguem preferências tarifárias." ${ }^{11}$ Os temas indicam não apenas a preocupação com comércio, mas também com o fortalecimento da estrutura institucional do Mercosul. Outro passo na direção do fortalecimento institucional do bloco foi dado em 2002, quando o CMC aprovou uma decisão sobre os símbolos do Mercosul, seu emblema e sua bandeira, com vistas a contribuir "para consolidar a identidade e a imagem do processo de integração"12.

Outro aspecto da estrutura institucional do Mercosul que funciona nesse período é seu mecanismo de solução de controvérsias. A possibilidade de estabelecimento de tribunais arbitrais pra resolver as disputas entre os Estadosmembros havia sido prevista no Protocolo de Brasília, de 1993. No entanto, é a partir de 1999 que o mecanismo é posto em prática. São dessa fase nove laudos arbitrais. A existência de uma quantidade maior de disputas entre os Estadosmembros reflete as crises em que estavam, mas o fato de os Estados as levarem aos órgãos de solução de controvérsias do Mercosul atesta o propósito de resolvê-las por meios institucionais. Dentre os nove casos levados ao julgamento do tribunal arbitral do Mercosul, apenas dois foram levados a nova arbitragem perante a $\mathrm{OMC}^{13}$. Em dezembro de 1999, o Brasil levou ao Tribunal Arbitral do Mercosul uma reclamação sobre a aplicação de medidas de salvaguarda sobre produtos têxteis, por parte da Argentina. Em fevereiro de 2000, enquanto o caso ainda não

9 Mercosul/CMC/DEC N ${ }^{\circ}$ 18/98, disponível em http://www.mercosur.int/msweb/portal\%20intermediario/ $\mathrm{pt} / \mathrm{index} \cdot \mathrm{htm}$

10 http://2005.sice.oas.org/trade/mrcsrs/decisions/indice3.asp\#2000

11 http://2005.sice.oas.org/trade/mrcsrs/decisions/dec3200p.asp

12 http://2005.sice.oas.org/trade/mrcsrs/decisions/dec1702p.asp

13 Os casos podem ser acessados em http://www.wto.org/english/tratop_e/dispu_e/dispu_e.htm 
havia recebido uma solução por parte do órgão do Mercosul, o Brasil solicitou um painel na OMC. Em 10 de maio, o Tribunal Arbitral do Mercosul considerou que as medidas adotadas pela Argentina não eram compatíveis com a normativa do Mercosul e deveriam ser revogadas. Em junho do mesmo ano, Brasil e Argentina notificaram à $\mathrm{OMC}$ que haviam chegado a uma solução negociada.

$\mathrm{O}$ segundo caso que foi levado à arbitragem da OMC também foi resultado de uma contenda entre Brasil e Argentina e ficou conhecido como o "caso dos frangos" (Giovanna \& Sálvio, 2006). A disputa referia-se à aplicação de medidas antidumping aplicadas pela Argentina às importaçôes de frangos inteiros. O Tribunal Arbitral do Mercosul aplicou as regras estabelecidas pelo acordo antidumping da $\mathrm{OMC}$, já que a normativa do Mercosul não contemplava a matéria. No entanto, o Brasil julgou que as regras foram aplicadas de forma diferente do que o painel da OMC faria e levou o caso à organização mundial, conseguindo ganhar a causa que havia perdido no tribunal do Mercosul.

Em 2002, o Protocolo de Olivos criou o Tribunal Permanente de Revisão (TPR), que poderia receber recursos de revisão dos laudos do Tribunal Ad Hoc. Este mesmo Protocolo estabeleceu que as controvérsias entre os Estados-membros poderiam ser submetidas a outros sistemas de solução de controvérsias, como na OMC. No entanto, uma vez iniciado o processo no foro escolhido, o Protocolo proibiu o recurso a outro mecanismo de solução de controvérsias, de qualquer uma das partes, para julgar a mesma matéria ${ }^{14}$.

É interessante notar que a partir de 1997 a proporção de votos coincidentes na AG da ONU aumenta e chega a 75\% do total. Nas 336 votações levadas a cabo entre 1997 e 2002, Brasil, Argentina, Paraguai e Uruguai votaram juntos em 253 casos e divergiram em apenas 83. Um dos fatores que pode ter contribuído para isso pode ter sido a adoção de uma norma aprovada em 1996 pelo CMC, que tratava da cooperação em foros internacionais. A Decisão no13/96 do CMC recomendava a coordenação das políticas e a atuação conjunta nos foros econômico-comerciais internacionais e destacava a coordenação na OMC, na ONU e na Associação Latino-Americana de Integração (Aladi) ${ }^{15}$. Além disso, conforme mencionado acima, em 1998 foi criado o Foro de Consulta e Concertação Política, com a função de aprofundar o diálogo entre os membros do Mercosul em temas de política externa.

\section{Econômico}

É no aspecto comercial que a fase compreendida entre 1998 e 2002 configura-se claramente como uma fase de crise para o Mercosul. O comércio intrabloco cai em 1999 25\% em relação ao ano anterior. Em 2000 há uma

14 Protocolo de Olivos, disponível em http://www.mercosur.int/msweb/portal\%20intermediario/pt/index.htm 15 MERCOSUL/CMC/DEC. No 13/96, disponível em http://2005.sice.oas.org/trade/mrcsrs/decisions/ DEC1396P.asp 
recuperação de $15 \%$ e o volume de comércio chega a US\$ 35.275 milhões. Mas uma nova queda, de $13 \%$, acontece em 2001 e o comércio intrabloco fecha o ano com um volume comercial interno de US\$ 30.545 milhóes. O ano de 2002 é o ano crítico: o volume comercializado entre os países do Mercosul cai 33\% em relação a 2001, para US $\$ 20.462$ milhões. Este número é menos da metade do volume comercializado pelo bloco em 1997, antes da crise, e representa quase um retorno ao volume de comércio de 1993, que havia sido de US\$19.143 milhões. A diferença entre 1997, o ano de pico, e 2002, o ano crítico, é de US\$ 20.612 milhôes, uma queda de 50,18\%.

No entanto não é apenas o comércio intrabloco que sofre uma diminuição nesse período. $\mathrm{O}$ volume negociado pelos países membros do Mercosul externamente ao bloco cai de US\$139.046 milhões em 1997 para US\$135.818 milhôes em 1998. E esse volume também tem uma trajetória de queda no ano seguinte, chegando a US\$ 122.922 milhões em 1999. Nos dois anos que se seguem, o comércio extrabloco ensaia uma recuperação, subindo para US\$ 135.945 milhōes em 2000 e para US\$ 138.965 milhões em 2001. Mas no ano de 2002, o ano crítico, o volume de comércio dos países do Mercosul com o resto do mundo sofre uma queda acentuada e fecha o ano em US\$ 128.132 milhôes.

Proporcionalmente, a importância do comércio intrabloco, em relação ao total de comércio dos países, também cai. Em 1997, o comércio entre os paísesmembros do Mercosul correspondia a 23\% do total de comércio. Esse patamar se mantém, nos primeiros anos dessa segunda fase, em torno dos $20 \%$. Mais uma vez, 2002 revela-se o ano crítico. Nesse ano a proporção do comércio intrabloco cai para $14 \%$ em relação ao total do comércio dos países do Mercosul.

O PIB também caiu nesse período, atestando uma fase de crise econômica geral. O PIB dos quatro sócios do Mercosul somados em 1997 ficara em US\$ 1.131.479,90 milhões e, em 1998, caiu para US\$ 1.117.255,40. Uma queda mais significativa aconteceu em 1999, quando a soma ficou em US\$ 848.424,00 milhôes. O nível mais baixo atingido pelo PIB dos quatro países durante toda a história do Mercosul aconteceu em 2002, quando a soma chegou a US\$ 579.803,50 milhōes, quase a metade do PIB de 1997.

Em janeiro de 1999, o Brasil desvalorizou sua moeda, o que provocou uma mudança significativa nas condições de competitividade intrabloco. A repercussão foi negativa, particularmente na Argentina, com o receio de uma invasão de produtos brasileiros ${ }^{16}$. Em 2001, com o agravamento da crise econômica, a Argentina anunciou medidas emergenciais que aumentaram algumas tarifas acima da tarifa externa comum do Mercosul. $\mathrm{O}$ acirramento das tensóes entre os dois países levou até mesmo ao cancelamento de uma visita que o presidente brasileiro Fernando Henrique Cardoso faria a Buenos Aires em abril de 2001'

16 Intal, Informe Mercosul, n. 11.

17 Banco de dados - Observatório Político Sul-americano: http://observatorio.iuperj.br/ 


\section{Social}

No que diz respeito ao turismo interno da região, curiosamente, apesar da crise, essa é a fase de maior circulação de pessoas. Enquanto na primeira fase o número médio de turistas por ano era de 3,9 milhões de pessoas, nessa segunda fase a média aumenta para 5,4 milhōes de turistas por ano. $\mathrm{O}$ movimento ascendente no número de turistas intrabloco, que vinha desde 1991, continua até 2000. É só em 2001, que esse número cai, em 24\%. Enquanto em 2000 circularam mais de 6,5 milhões de pessoas, em 2001 foram pouco mais de cinco milhōes. Em 2002, o ano crítico, esse número caiu mais 30\% em relação ao ano anterior: foram apenas 3,5 milhões de turistas na região, um número bastante próximo dos indicadores de 1992 e 1993. No total, entre 2000, o ano de maior número de turistas, e 2002, houve uma queda de $47 \%$ no número de turistas circulando intrabloco.

\section{$3^{\text {a }}$ Fase III (desde 2003): revitalização do Mercosul}

\section{Institucional}

A partir de 2003, a estrutura institucional do Mercosul passou por novas mudanças, com a ampliação da agenda do processo de integração. Houve um impulso de criação de novos órgãos, com destaque para a preocupação com assuntos mais diversos do que os comerciais, com a inclusão de instituições para tratar de direitos humanos, democracia e questóes sociais.

A retomada coincide com mudanças nos governos da região nesse período. No Brasil, Luiz Inácio Lula da Silva, que tomou posse em janeiro de 2003, defendia em seu programa de governo a necessidade de revigorar o Mercosul. Na Argentina, Néstor Kirchner assumiu o poder em maio, com um posicionamento favorável ao fortalecimento do Mercosul, às expensas da Área de Livre Comércio das Américas (Alca). No Uruguai. Tabaré Vázquez foi eleito em 2004, por uma coligação de esquerda, com a proposta de trabalhar pelo relançamento do Mercosul e sua reforma institucional ${ }^{18}$.

Em 2003, foi criada a Comissão de Representantes Permanentes do Mercosul (CRPM), com sede em Montevidéu. Suas principais atribuições são assistir o Conselho do Mercado Comum e a Presidência Pro-Tempore do Mercosul em todas as atividades que sejam requeridas por qualquer deles; apresentar iniciativas ao Conselho do Mercado Comum sobre matérias relativas ao processo de integração do Mercosul, às negociaçōes externas e à conformação do Mercado Comum; fortalecer as relaçôes econômicas, sociais e parlamentares no Mercosul, estabelecendo vínculos com a Comissão Parlamentar Conjunta e o

18 Banco de dados - Observatório Político Sul-americano: http://observatorio.iuperj.br/ 
Foro Consultivo Econômico e Social, assim como com as Reuniōes Especializadas do Mercosul ${ }^{19}$.

Em 2004, foram criados, dentro do âmbito do CMC, a Reunião das Altas Autoridades nas Áreas de Direitos Humanos e o Foro Consultivo de Municípios, Estados Federados, Províncias e Departamentos do Mercosul. Além disso, também são de 2004 a criação do Centro Mercosul de Promoção do Estado de Direito e o estabelecimento de um Grupo de Alto Nível para a criação de uma Estratégia Mercosul de Crescimento do Emprego. A criação desses órgãos indica a preocupação com a ampliação do escopo do projeto de integração, com a inclusão mais efetiva de temas como democracia, direitos humanos e questóes sociais no âmbito do Mercosul, assim como a incorporação de atores subnacionais como participantes do processo, embora ainda com status apenas consultivo.

É também nessa fase que começa a ser tratado o tema das assimetrias no Mercosul. Em 2004 foi criado o Fundo de Convergência Estrutural do Mercosul (Focem), destinado a promover a competitividade e a coesão social dos Estados Partes, reduzir as assimetrias - em particular dos países e regiōes menos desenvolvidas (...), impulsionar a convergência estrutural no Mercosul e fortalecer a estrutura institucional do processo de integração. ${ }^{20} \mathrm{~A}$ criação do Focem atende a demandas dos sócios menores do bloco, Paraguai e Uruguai, que manifestavam sua frustração com relação ao processo de integração. O Focem tem caráter redistributivo e representa a disposição de Brasil e Argentina em arcar com certos custos da integração, uma vez que são os maiores contribuintes do fundo, mas recebem a menor parte dos recursos.

Em dezembro de 2005, o CMC aprovou o Protocolo Constitutivo do Parlamento do Mercosul21 ${ }^{21}$ e em dezembro de 2006 o Parlamento foi efetivamente inaugurado. Em sua primeira legislatura (2007-2010), está formado por representantes dos parlamentos dos Estados-Partes, mas a partir de 2011, o Protocolo prevê que seus integrantes sejam eleitos por sufrágio direto, universal e secreto. Embora signifique um avanço na estruturação institucional do bloco, o Parlamento do Mercosul avançou pouco em relação às funções exercidas pela CPC e continua tendo caráter apenas consultivo, sem nenhum competência legislativa. Além da função principal de acelerar os correspondentes procedimentos internos para a entrada em vigor das normas nos Estados Partes, cabe também ao Parlamento elaborar e publicar relatórios sobre a situação dos direitos humanos nos Estados Partes, realizar reuniões semestrais com o Foro Consultivo Econômico-Social a fim de intercambiar informações e opiniões sobre o desenvolvimento do Mercosul, e organizar reuniões

19 Mercosul/IV CMC EXT/DEC No 11/03, disponível em http://www.mercosur.int/msweb/portal\%20 intermediario/pt/index.htm

$20 \mathrm{Mercosul} / \mathrm{CMC} / \mathrm{DEC}$. No 45/04, disponível em http://www.mercosur.int/msweb/portal\%20 intermediario/Normas/normas_web/Decisiones/PT/DEC_045_04_Fundo\%20Estrutural_Ata_02_04. PDF

$21 \mathrm{Mercosul} / \mathrm{CMC} / \mathrm{DEC}$ No 23/05, disponível em http://www.mercosur.int/msweb/portal\%20intermediario/ Normas/normas_web/Decisiones/PT/DEC_023_005_Acordo\%20\%20Parlamento_PT.PDF 
públicas com entidades da sociedade civil e os setores produtivos sobre questôes vinculadas ao desenvolvimento do processo de integração. ${ }^{22}$

Em 2006, o CMC propôs a criação de duas novas instituições: o Observatório da Democracia no Mercosul (ODM) e o Instituto Social do Mercosul (ISM). Ambos foram criados no início de 2007. O Observatório foi criado levando em consideração a necessidade de que o Mercosul acompanhe o desenvolvimento social e democrático de seus Estados-membros. Até sua criação, o CMC instituiu um corpo de observadores dos Estados-partes para cada processo eleitoral ocorrido nos países do Mercosul ${ }^{23}$. O Instituto Social visa trazer para a estrutura institucional do bloco a "importância de aprofundar o desenvolvimento dos temas sociais no Mercosul".Em 2007 foi criado também o Instituto Mercosul de Formação (IMEF), com o objetivo de "estabelecer no Mercosul um âmbito acadêmico para a capacitação e especialização dos fúncionáios públicos na temática da integração regional". ${ }^{24}$

Em relação à internalização das diretrizes da CMC, entre 2003 e 2006 entraram em vigor 16 normas. Dessas, quatro eram normas aprovadas na fase anterior e as 14 restantes eram normas aprovadas a partir de 2003, de um total de 16 diretrizes emanadas da CMC nesse período e que necessitavam de incorporação aos ordenamentos jurídicos nacionais. As outras duas diretrizes requeriam internalização do Brasil, o que aconteceu em 2006, com previsão de entrada em vigor em 2007. O período teve ainda duas diretrizes revogadas.

No âmbito da representação externa do bloco, há uma queda no percentual de votos coincidentes na AG da ONU. Nas 220 votações da AG entre 2003 e 2005, os quatro países-membros do Mercosul votaram juntos em 152, o que corresponde a $69 \%$ do total. Embora represente uma queda em relação aos $75 \%$ de votos juntos na fase anterior, ainda é um percentual bastante mais expressivo do que os $51 \%$ da fase de formação do Mercosul.

\section{Econômico}

Os indicadores econômicos voltam a crescer, indicando uma nova fase positiva para o Mercosul. O PIB somado dos quatro países do Mercosul se recupera nessa fase. Após uma queda de US\$ 804.087,70 milhões em 2001 para US $\$ 579.803,50$ milhões em 2002 , ele se recupera um pouco em 2003 , somando US\$ 651.929,40 milhões. Em 2004 e 2005, o PIB continua crescendo e termina o ano em US \$ 777.185,50 milhões e US\$ 1.003 .129 milhões, respectivamente.

Os indicadores comerciais também apresentam uma recuperação. $\mathrm{O}$ volume de comércio intrabloco, que havia sido de US\$ 20.462 milhões em 2002, tem

22 Sobre o Parlamento do Mercosul, ver Ribeiro Hoffmann 2007.

23 http://2005.sice.oas.org/trade/mrcsrs/decisions/dec2406p.pdf

24 http://www.mercosur.int/msweb/Normas/normas_web/Decisiones/ES/2007/DEC\%20004-2007_ES_ InstitutoMercosurFormacion.pdf. Ver também http://2005.sice.oas.org/trade/mrcsis/decisions/dec1906p. pdf. e http://www.mre.gov.br/portugues/imprensa/nota_detalhe.asp?ID_RELEASE = 4179 
uma recuperarão de $25 \%$ em 2003 e termina o ano em US \$ 25.597 milhões. Nos dois anos seguintes, o crescimento continua. $\mathrm{O}$ volume total de comércio intrabloco fecha 2004 em US\$ 34.640 milhôes, num crescimento de 35\% em relação ao ano anterior, um recorde na história do bloco regional. Em 2005, o comércio cresce mais $21 \%$ e o total chega a US\$ 42.142 milhões, ultrapassando pela primeira vez o volume de comércio intrabloco de 1997, o último ano antes que os efeitos da crise econômica se fizessem sentir.

O comércio dos países do Mercosul com o resto do mundo também cresce no período. O montante sobe de US\$ 128.132 milhões em 2002, para US\$ 146.642 milhões em 2003, um crescimento de $14 \%$. Isso significa que o comércio intrabloco se recuperou mais rapidamente, com um crescimento de $25 \%$ logo no primeiro ano após a fase de crise, contra um crescimento de $14 \%$ do comércio extrabloco no mesmo período. Em 2004, enquanto o comércio intrabloco crescia $35 \%$, o comércio extrabloco cresceu 30\% e alcançou US\$ 191.920 milhōes. Em 2005, novo crescimento, dessa vez de $21 \%$ e o volume total chegou a US\$ 230.710 milhōes.

Proporcionalmente, o comércio intrabloco não recupera o patamar anterior à crise. Embora tenha chegado a representar 23\% do total de comércio dos países-membros, em 1997 e 1998, após o ano crítico de 2002 essa proporção se estabiliza em torno dos $15 \%$. Ainda assim, é interessante notar que o volume total de comércio cresce muito nesse período, chegando a um patamar que não havia sido alcançado antes. Dessa forma, apesar de estabilizado em 15\% do total, o volume de comércio intra-Mercosul, também alcança cifras bastante expressivas para o histórico da região.

\section{Social}

O número de turistas da região volta a crescer lentamente nessa fase. Nos dois primeiros anos, a circulação de pessoas varia muito pouco: de 3,5 milhões de turistas em 2002, para 3,6 milhões de turistas em 2003, o que representa um aumento de apenas $4 \%$. O número de turistas circulando entre os países do bloco continua a crescer nos anos seguintes, chegando a 4,3 milhões de pessoas em 2005. Apesar de representar um aumento de $25 \%$ em relação a 2002 , esse número ainda é bem bastante inferior aos 6,5 milhōes de turistas de 2000 . A média anual dessa fase é de 4 milhões de turistas intrabloco.

\section{Conclusão}

Este estudo apresentou a necessidade de uma consideração multidimensional do processo de integração do Mercosul. Os indicadores quantitativos e qualitativos observados na pesquisa sugerem um quadro de integração regional variável no tempo e nos temas. Ainda que em sua dimensão comercial o Mercosul 
tenha estagnado e mesmo retrocedido, sobretudo no segundo período analisado, o mesmo não ocorreu em outras áreas, tais como a politico-institucional e a social.

Os dados compilados neste trabalho e outras referências na literatura especializada recente (Lima e Coutinho, 2007) apontam para uma mudança paradigmática no bloco. Um modelo regionalista estrutural, voltado mais para aspectos físicos, energéticos, institucionais e sociais, está sendo aos poucos construído. Embora essa mudança seja lenta, seus sinais já são perceptíveis, o que não significa dizer que a integração comercial tenha sido de todo abandonada frente às dificuldades políticas e assimetrias econômicas.

Ao contrário de análises conjunturais de curto-prazo e unidimensionais, muitas dessas sem respaldo empírico, é possível dizer com bases nas informaçōes disponíveis que a integração regional continua se desenvolvendo. A discussão sobre o caráter do bloco, intergovernamentalista, equivocadamente leva parte dos especialistas a considerarem que o Mercosul se reduz a um acordo de cooperação sem grandes conseqüências institucionais. Não raramente, observam-se críticas dirigidas à suposta fragmentação verificada nos últimos anos, tendo em vista todos os desentendimentos entre Estados-membros tais como os em função do debate das assimetrias e da crise das papeleiras.

A literatura sobre integração regional geralmente atrela o conceito de institucionalização à supranacionalidade e ao nível de juridicização. Este trabalho, contudo, revelou que processo de institucionalização de integração regional não se limita a um modelo específico, e que sua restrição ao caráter supranacional ou jurídico é uma atitude eurocentrada e simplificadora. Um olhar multidimensional sobre a integração regional percebe outros critérios de institucionalização além da supranacionalidade e da legalização, ainda que estes sejam bastante relevantes, uma vez que se referem à autonomia das instituições regionais.

Além da autonomia, pelo menos outros três critérios de institucionalização podem ser utilizados: adaptabilidade, complexidade e coesão. Ao longo de sua história, o Mercosul demonstrou capacidade de se adaptar ao contexto, superando uma grande crise e mudanças profundas; uma crescente variedade de instituiçóes e temas, diversificando-se para além da questão comercial; e uma capacidade de ação coletiva em fóruns multilaterais.

Essa visão multidimensional da integração regional não absolve os problemas e as restrições do Mercosul. Ela permite, no entanto, que se perceba que o bloco avança, ainda que escape ao modelo dominante na primeira metade da década de 1990, ou às expectativas originais. A superação de uma grande crise econômica, a criação de novos órgãos, novas competências, a ampliação da área de atuação, a prioridade conferida pelos seus respectivos governos e as ações conjuntas indicam a continuidade do processo de integração. 


\section{Referências bibliográficas}

ABBOTT, Kenneth O.W.; Moravcsik, Andrew; Slaughter, Anne-Marie; Snidal, Duncan (2000): The Concept of Legalization; in: International Organization 54: 3.

BELASSA, B (1961) Theory of Economic Integration. Homewood, IL: R.D.Irwin.

COUTINHO, Marcelo; RIBEIRO HOFFMANN, Andrea; KFURI, Regina. (2007) Raio-X da Integração Regional. Observatório Político Sul-Americano, disponível em http:// observatorio.iuperj.br/pdfs/1_estudosecenarios_Estudos_Coutinho_Ribeiro_Kfuri.pdf.

FINNEMORE, Matha e TOOPE, Stephen (2001) Alternatives to 'Legalization'. Richer Views of Law and Politics; in: International Organization 55: 3

GIOVANNA, G.; SÁLVIO, L. Reflexões sobre o mecanismo de solução de controvérsias do Mercosul e o impacto de suas decisões no mecanismo de solução de controvérsias da OMC. Cebri artigos, v.4, 2006.

HAAS, Ernst B., The Uniting of Europe and the Uniting of Latin America, Journal of Common Market Studies 5:4, 1967.

HERZ, Monica, RIBEIRO HOFFMANN, Andrea, Organizacoes Internacionais. Historia e Praticas, Rio de Janeiro, Ed.Campus, 2004.

HUNTINGTON, Samuel (1975). A Ordem Política nas Sociedades em Mudança. Rio de Janeiro: Forense-Universitária; São Paulo, Ed. da Universidade de São Paulo.

LIMA, Maria Regina Soares de e COUTINHO, Marcelo "Uma versão estrutural do regionalismo". in: Eli Diniz (org), "Globalização, Estado e Desenvolvimento: dilemas do Brasil no novo milênio". Rio de Janeiro: Editora FGV, 2007.

MAGALHAES, Bruno. O papel do Mercosul: a crise das papeleras e o processo de integracao regional sul-americano. Observatório Politico Sul-Americano. observador online Vol.1 No.6 Disponivel em: http://observatorio.iuperj.br/archive/Observador_v_1_n_6.pdf, 2006.

MALAMUD, Andres Presidential Democracies and regional integration. An institutionalist approach to Mercosur (1985-2000), doctoral dissertation, European University Institute, 2003.

NYE, J., Comparing Common Markets: A Revised Neofunctionalist Model, International Organization, 24:4, 1970.

PASQUARIELLO MARIANO, Karina L. As cidades no atual contexto internacional e nos processos de integração regional. Trabalho apresentado na ANPOCS 2007.

RIBEIRO HOFFMANN, Andrea A representação do Mercosul nas organizações e negociações internacionais. Radar do Sistema Internacional / CGEE. Disponível em: http://www.rsi. cgee.org.br/, 2007.

RITTBERGER, Berthold e SCHIMELFENNIG, Frank, The Constitutionalization of the European Union, Journal of European Public Policy 13: 8, 2006.

\section{Resumo}

No trabalho são desenvolvidos indicadores de integração regional com o principal objetivo de apresentar uma analise multidimensional do Mercosul no período de 1991 a 2006. 
A pesquisa parte da premissa que o Mercosul não é um caso sui generis de integração regional, e sim um exemplo de organização de integração regional assim como, por exemplo, a União Européia ou a Comunidade Andina de Nações. Assim, embora os indicadores sejam desenvolvidos para serem aplicados no Mercosul, eles poderiam potencialmente ser aplicados para outros casos de processos de integração regional.

\section{Abstract}

The present work develops indicators of regional integration in order to conduct a multidimensional analysis of Mercosur in the period of 1991 to 2006. One premise is that Mercosur cannot be considered a sui generis case but an example of regional integration organization such as the European Union or the Andean Community of Nations. In that sense, although the indicators are developed to be applied in Mercosur, they could be applied in other organizations of regional integration.

Palavras-chave: Integração regional, organização regional, Mercosul, análise multidimensional.

Key words: regional integration, regional organization, Mercosur, multidimensional analysis. 